\title{
JOGO DAS GRANDEZAS: UM RECURSO PARA O ENSINO DE FÍSICA
}

\author{
Everaldo dos Santos Araúuo, Bianca Martins Santos \\ Centro de Ciências Biológicas e da Natureza, Universidade Federal do Acre, \\ Campus Sede, Rodovia BR 364, Km 04, s/n, Distrito Industrial, Rio Branco, AC, \\ CEP 69920-900.
}

\begin{abstract}
Resumo
O presente artigo propõe ao ambiente escolar um jogo educativo para o ensino de Física, sobre as grandezas físicas e seus significados, com intuito de alcançar a participação dos alunos no processo de ensino-aprendizagem. O jogo envolve os principais temas abordados em física durante o ensino médio: mecânica, ondulatória, óptica, termodinâmica, eletromagnetismo e física moderna; viabilizando o uso em salas de aula do terceiro do ensino médio ou em turmas dos cursos de nível superior em Física, para revisão dos conteúdos. A presente pesquisa, além de propor o "Jogo das Grandezas" como recurso didático, apresenta resultados para sua aplicação com alunos da graduação, concluintes do curso de Licenciatura em Física da Universidade Federal do Acre. Os resultados mostram que a dinâmica do jogo foi proveitosa, com grande aceitação por parte dos pesquisados, que demonstraram habilidades e segurança em relação aos conteúdos de Física, evidenciando instantes de descontração e seriedade durante a atividade. Verificou-se ainda que o jogo proposto é um instrumento promissor para o ensino de física.
\end{abstract}

Palavras-chave: Ensino de Física; Jogo Educativo; Grandezas físicas; Lúdico; Recurso didático.

\footnotetext{
*E-mail: everaldofisicomatematicoufac@gmail.com
} 


\begin{abstract}
The present article proposes to the school environment an educational game for teaching of physics, about physical quantities and their meanings, with objective to achieve the participation of students in the teaching-learning process. The game involves the main topics discussed in physics during high school: mechanics, wave, optics, thermodynamics, electromagnetism and modern physics; enabling the use in classrooms of the third year of high school or in classes of undergraduate courses in Physics, for review of the physics contents. The present research, besides proposing the "Game of Quantities" as didactic resource, presents results for your application with graduation students that were been forming in Degree in Physics of the Federal University of Acre. The results show that the dynamics of game was beneficial, with great acceptance by the researched, who demonstrated skills and safety in relation to the contents of Physics, evidencing moments of relaxation and seriousness during the activity. It was also verified that the proposed game is a promising instrument for the teaching of physics.
\end{abstract}

Keywords: Physics Teaching; Educational Game; Physical quantities; Ludic; Didactic resource.

\title{
1 INTRODUÇÃO
}

Hodiernamente existem diversas teorias de ensino e aprendizagem que fornecem ao professor meios para compreender como esse processo ocorre. Tornar-se conhecedor dos estudos desenvolvidos ao longo dos anos sobre como o indivíduo aprende (Moreira, 2015), facilita ao docente o planejamento de suas aulas. Segundo Paulo Freire (2011), a relação entre professor e aluno está baseada na troca e não apenas na transmissão do conhecimento, onde o objetivo não é apenas a aquisição de conhecimentos, por parte do aluno, mas também desenvolver nos estudantes habilidades como a autonomia, a criatividade, entre outras. Freire (2011, p. 25) ainda afirma "Quem ensina aprende ao ensinar, e quem aprende ensina ao aprender". Neste contexto, é importante ressaltar o que diz Novak (1977) quando traz em sua teoria de aprendizagem que a experiência afetiva é positiva e intelectualmente construtiva quando o aprendiz tem ganhos em compreensão.

É conhecido o fato de que em grande parte das escolas de ensino médio, o ensino de física ocorre da forma tradicional (Bezerra, 2009), promovendo nos alunos a aversão pela disciplina, tida geralmente como "difícil" (Ricardo, 2007; Moraes, 2009). Nesta perspectiva, deve-se repensar formas de como melhorar a formação inicial e continuada de professores (Carvalho, 2011).

Para que os alunos não fiquem apenas sentados executando tarefas na sala de aula, é necessário despertar o interesse desse aluno para o aprendizado. Segundo Piaget apud Puloski (1983, p. 87),

...quando a criança se interessa pelo que faz, é capaz de empreender esforços até o limite de sua resistência física. Apenas quando as crianças se empenham em sua própria aprendizagem, apenas então tomará forma a verdadeira disciplina - a disciplina que as próprias crianças desejam e aprovam. 
Assim, quando o aluno está envolvido no processo de ensino, desempenhando o papel de protagonista do saber, participando ativamente das aulas, a aprendizagem pode ocorre de forma facilitada. Vale mencionar que a citação de Piaget diz respeito a crianças, e não vale automaticamente para universitários, o público alvo onde o jogo proposto foi aplicado.

Observe que o método tradicional de ensino, baseada na simples transmissão de conteúdo, sem permitir ao aluno a participação no processo de construção do conhecimento, torna-se ultrapassado(Moreira, 2017). O ensino ditatorial, sem interação dos estudantes, desvia-se dos objetivos descritos nos Parâmetros Curriculares Nacionais do Ensino Médio - PCNEM (2002, p. 59) de possibilitar a "formação de um cidadão contemporâneo, atuante e solidário, com instrumentos para compreender, intervir e participar na realidade". Para alcançar tais propósitos, o docente deve desempenhar o papel de professor-pesquisador (Schnetzler, 2002), observando a sua prática e repensando suas metodologias de ensino, de forma a encontrar em seu alunos indícios de aprendizado. Neste sentido, novos métodos e recursos didáticos estão sendo amplamente desenvolvidos e utilizados por diversos grupos de pesquisa na área de ensino de física.

Como exemplo, menciona-se aqui a gincana mesclada com experimentos,conforme apresentado por Castelo Branco e Moutinho (2015), que trazem resultados satisfatórios para o uso de tal recurso. Tirinhas e Histórias em Quadrinhos também são apresentados como um recurso para aulas de ciências, estabelecendo uma ponte entre a realidade do aluno e os conceitos científicos ensinados, proporcionando a interação entre os alunos (Pereira, 2016). Além do uso da cinematografia atual, Piassi (2013, p. 165) apresenta propostas de ensino de ciências com o uso da ficção científica, constatando que o

...professor pode incentivar os estudantes a procurarem seus próprios interesses dentro da ficção científica, sugerindo obras e autores de seu interesse, e confrontando as visões de mundo e as técnicas narrativas e a relação com o conhecimento científico...,

levando o "estudante a aprender a identificar, apreciar e analisar, com mais senso crítico e exigência"(Piassi, 2013, p. 166) os efeitos cinematográficos.

Outra tendência que tem ganhado espaço na literatura relacionada ao ensino de ciência, se refereao uso de simuladores e animações como ferramentas para auxiliar o aprendizado (Heckler, 2007). Além do uso dos tradicionais laboratórios de experimentos, que proporciona um aprendizado significativo, quando o aluno participa efetivamente da prática de laboratório. Borges (2002) descreve algumas alternativas potencialmente relevantes e pedagogicamente interessantes para o uso de laboratórios escolar de ciências. Dentro do tema de aulas experimentais, Cardoso e Paraíso (2014) compõem um mapa dos cenários discursivos que permeiam a produção acadêmica brasileira de artigos em periódicos e eventos, teses e dissertações relacionados a esta temática.

Entre a diversidade de recursos didáticos disponíveis na literatura, o presente trabalho se concentra em propor e utilizar o "Jogo das Grandezas" como recurso didático para o ensino de física, idealizado pelos autores do trabalho e aperfeiçoado a longo de suas aplicações. Através do método lúdico buscou-se despertar o interesse dos alunos, proporcionando um ambiente prazeroso, onde o professor desempenha papel fundamental para a construção do conhecimento e a validação da atividade realizada em grupo. Vale ressaltar que o lúdico dispõe de multifuncionalidade, possibilitando trabalhar com os mais diversos conteúdos além de estabelecer a conexão entre eles, de acordo com os objetivos que o educador pretende atingir com o público alvo. Schwarz (2006, p. 35) afirma que 
...os jogos estão tão amplamente disseminados por todas as culturas, por serem prazerosos e se adaptarem às diversas fases do desenvolvimento humano, promovendo aprendizagens. Eles são praticados por adultos e por crianças devido a sua adaptabilidade aos mais diversos interesses e necessidades.

Observe que por envolver um público de faixa etária ampla, tal recurso pode ser pensado e aplicado para a educação infantil, como para turmas da educação de jovens e adultos. Além de favorecer o interesse pelas atividades escolares, e consequentemente ajudar no aprendizado dos conteúdos como sugerido por Gomes e Friedrich (2001, p. 42), “...o jogo didático pode ser utilizado para atingir determinados objetivos pedagógicos, sendo uma alternativa para se melhorar o desempenho dos estudantes em alguns conteúdos de difícil aprendizagem."

Assim o jogo didático não se restringe apenas a um instrumento facilitador da transmissão do conteúdo, mas acaba por auxiliar em outros fatores de grande importância no ensino. De acordo com Rego (2001, p. 83)

...as interações sociais (entre os alunos e o professor e entre as crianças) no contexto escolar passam a ser entendidas como condição necessária para a produção de conhecimento por parte dos alunos, particularmente aquelas que permitam o diálogo, a cooperação e troca de informações mútuas, o confronto de pontos de vistas diferentes e que implicam na divisão de tarefas onde cada um tem uma responsabilidade que, somadas, resultarão no alcance de um objetivo em comum.

Acrescenta-se o fato de que "o jogo pode deixar nos estudantes marcas emocionais que os ajudam a reconhecer sua capacidade de aprender ciência e tornar o conteúdo mais facilmente compreensível e recordável" (Messeder Neto, 2017, p. 523). Claramente apesar dos benefícios na utilização dos jogos didáticos como meio de ensino, dependerá de esforços e comprometimento tanto do professor e alunos. Cabendo ao professor o papel principal, em planejar a aplicação desse método, assim como, ter bem definidos os objetivos que se deseja alcançar com essa atividade para avaliar os resultados obtidos e consequentemente ter sucesso na sua prática. Como citado por Schwarz (2006, p. 27):

...dimensão lúdica [...] qualifica as tarefas escolares”,porém isso só acontece quando as atividades forem planejadas, organizadas e direcionadas para esse fim e utilizadas de forma adequada. Reforça a mesma orientação, com ênfase maior na forma de conduzir as atividades: "a 'melhor das técnicas' ou o 'melhor método' podem ser desvirtuados, anulando-se, por mal conduzidos, todo o benefício que poderia trazer aos alunos.

Utilizando a abordagem de jogos pedagógicos, a presente pesquisa baseia-se na utilização do pensamento de que o lúdico é uma estratégia a ser usada como estímulo na construção do conhecimento e desenvolvimento das diferentes habilidades de cada indivíduo. O principal objetivo do trabalho é propor o "Jogo das Grandezas" como forma de avaliação de conhecimentos teórico em física e proporcionar aos jogadores estabelecer correlação entre a teoria e o cotidiano. Além de apresentar resultados para sua aplicação, o trabalho tem a finalidade, através do uso do jogo pedagógico, instigar os alunos a relembrarem ou aprenderem os conteúdos já trabalhados em sala de aula.

Como o jogo proposto trabalha-se os principais assuntos estudados no ensino médio, o mesmo pode ser usado como instrumento avaliativo para o professor reconhecer as principais dificuldades apresentadas 
Revista do Professor de Física • Brasília, vol. 2, n. 2 • 2018

pelos estudantes, proporcionando ao docente elaborar uma melhor adequação na forma de ensino sobre os conteúdos que os alunos demonstram dificuldade. O jogo permite uma competição saudável e proveitosa entre os estudantes, sem cobranças por parte dos professores, pois os discentes apenas competem entre si, através de equipes, grupos ou até mesmo jogadores individuais. Nesse cenário, o jogo proposto pode ser utilizado em turmas de terceiro ano do ensino médio ou em turmas de últimos períodos da graduação, pois o mesmo engloba os principais assuntos de física, como: mecânica, ondulatória, óptica, termodinâmica, eletromagnetismo e física moderna. Para os resultados do presente trabalho, o jogo foi utilizado com uma turma de 8o. período, concluintes do curso de Licenciatura em Física, da Universidade Federal do Acre (UFAC) e ao final da atividade, um questionário investigativo foi aplicado para avaliação do recurso utilizado.

\section{METODOLOGIA DA PESQUISA E REGRAS DO “JOGO DAS GRANDEZAS"}

A metodologia consiste na aplicação do "Jogo das Grandezas", inicialmente em fase de teste, para turma de primeiro período do Curso de Licenciatura da UFAC, durante a disciplina de Instrumentação do Ensino de Física I, no período letivo de 2017-1. Após adaptações e melhorias no jogo, o mesmo foi aplicado na turma de oitavo período para os concluintes do Curso de Licenciatura em Física da UFAC, na aula de Instrumentação do Ensino de Física V, ao longo do período letivo de 2017-2. O jogo proposto foi desenvolvido com base nos conceitos aqui apresentados e nos conteúdos específicos contidos em livros didáticos de física para o ensino médio.

O layout do jogo está apresentado na Figura 1, o mesmo inicia-se com uma roleta com três pontas, nesse caso utilizou-se o brinquedo spinner, onde cada ponta identifica o grupo ou o jogador individual, contemplando ao total três jogadores (A, B e C). Cada divisão da roleta indica um dos seis assuntos estudados em física e contemplados no jogo (mecânica, ondulatória, óptica, termodinâmica, eletromagnetismo e física moderna). Para cada tema existe uma correspondente pilha de cartas com os nomes de grandezas físicas relacionadas ao tema, veja o layout das cartas na Figura 2 e exemplos de grandezas descritas em algumas cartas na Figura 3. O total de cartas são 104.

A dinâmica do jogo consiste em rodar a roleta, em seguida retirar uma carta da correspondente pilha determinada pela roleta e na sequência responder a pergunta. A regra do jogo determina que para cada acerto o jogador avança uma casa e a cada erro o jogador permanece na casa onde está, dentro da trilha de casas visualizada no lado direito da Figura 1.

O jogo inicia-se com os alunos divididos em três grupos: $\mathrm{A}, \mathrm{B}$ e C, no qual esta divisão fica a critério dos jogadores ou do professor. Após rodar a roleta, o local ondeparar as respectivas letras do spinner (A, B e C), indicam as pilhas de cartas que cada grupo deverá retirar uma carta. Vale ressaltar que nas cartas estão escritos nomes de grandezas físicas. Considere a seguinte situação por exemplo, a ponta do

spinner A apontou para ondulatória, a B para Óptica e C para Física moderna, conforme a Figura 1. Nesse exemplo, cada grupo deve tirar uma carta da respectiva pilha: ondulatória, óptica e física moderna. Nas cartas sorteadas estarão descritas grandezas físicas, por exemplo: comprimento de onda, foco e constante de Planck, respectivamente, segundo o exemplo citado. Nesse caso os jogadores ou as equipes deverão 


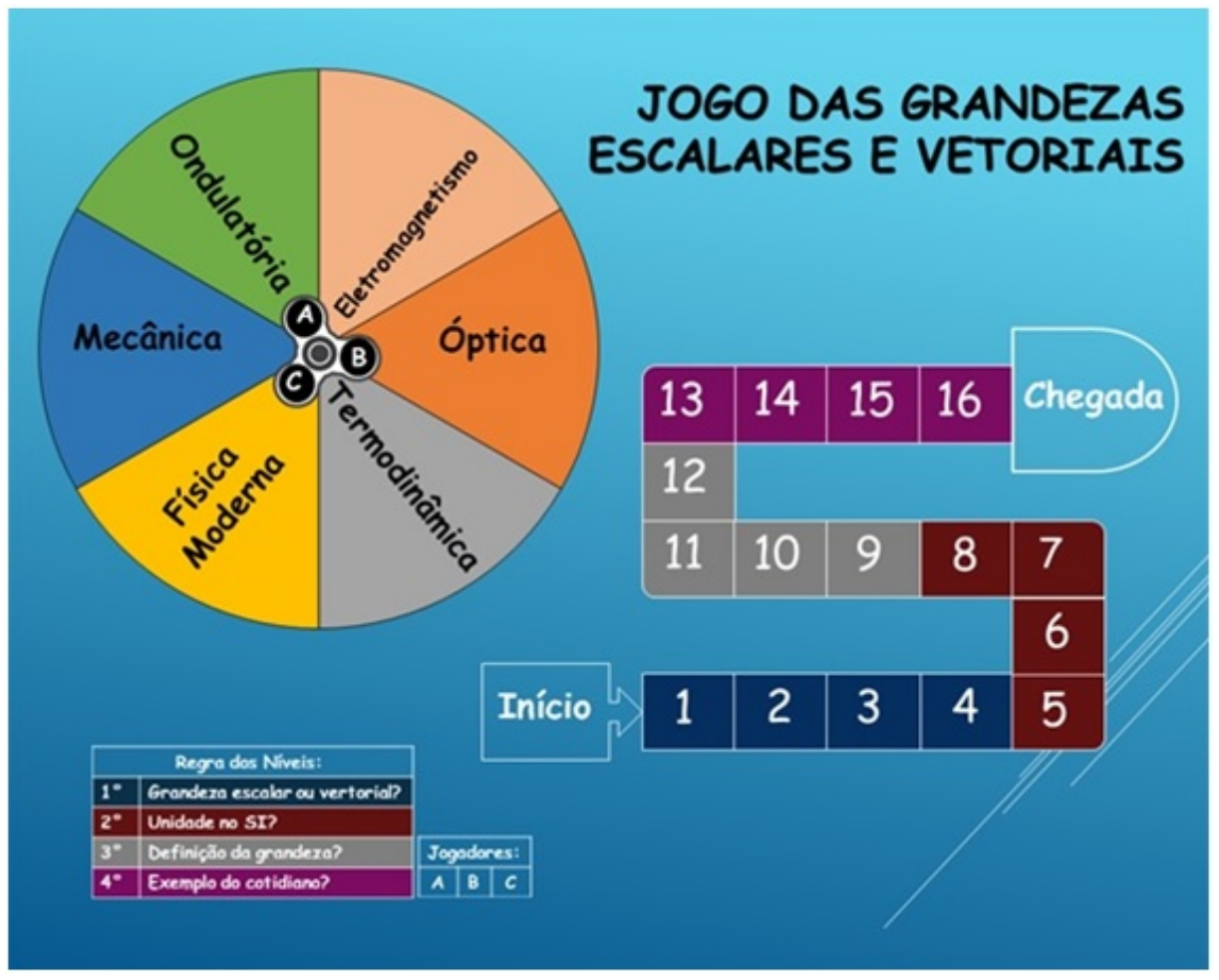

Figura 1: Layout do Jogo das Grandezas.
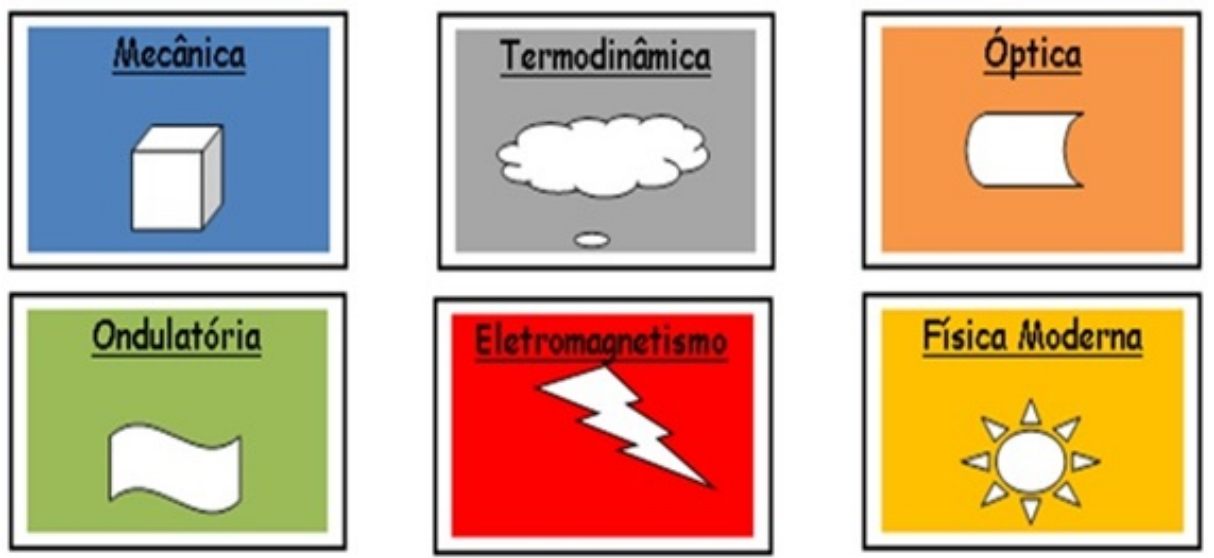

Figura 2: Layout das cartas do Jogo das Grandezas. 

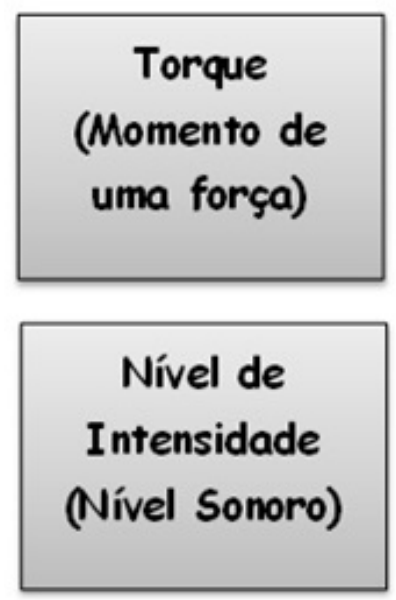
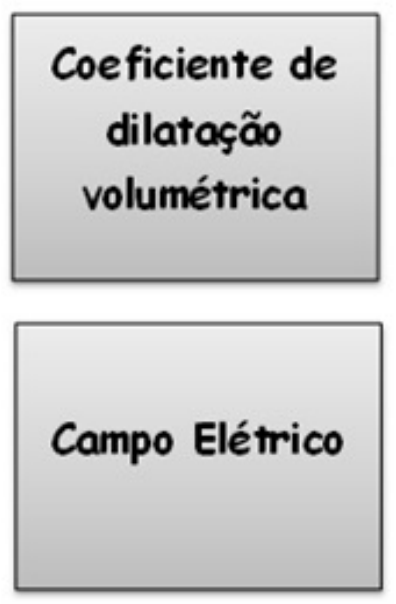
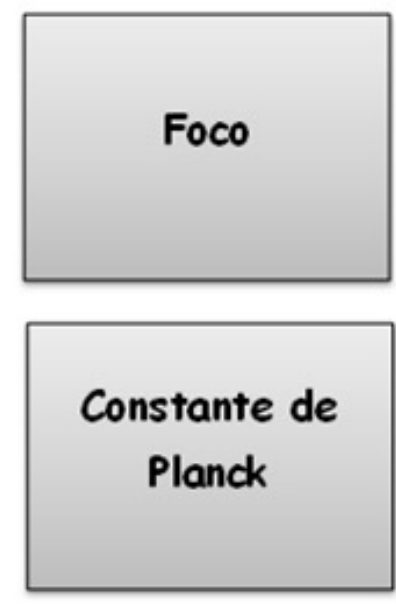

Figura 3: Alguns exemplos de grandezas descritas nas cartas do Jogo das Grandezas.

informar o que é requerido em cada nível da trilha de casas: o tipo de grandeza, a unidade, a definição física ou o exemplo do cotidiano, conforme descrito a seguir.

Na Figura 1 é possível observar a trilha de casas que indica o caminho do jogo, onde está determinado o início e o final do jogo. A trilha de casas está representada com quatro cores diferentes: azul escuro, marrom, cinza e roxo; correspondendo respectivamente aos níveis: primeiro, segundo, terceiro e quarto. No primeiro nível o jogador terá que informar qual o tipo de grandeza (escalar ou vetorial), a equipe ou jogador que alcançar o segundo nível terá que informar a unidade de medida no Sistema Internacional de Unidades (SI). No terceiro nível os jogadores terão que dar a definição da grandeza física e no quarto nível citar um exemplo da grandeza no cotidiano.

Cada equipe terá 1 minuto para responder a questão e todos os integrantes dos grupos podem discutir a resposta, porém, será aceita apenas uma resposta por equipe. Para tal atividade, pode ser permitida a consulta ao livro didático ou ao caderno, segundo o critério do professor. Na oportunidade não foi permitida a consulta no livro e na internet, entretanto o docente tem a liberdade para determinar quais materiais os participantes do jogo podem consultar. O jogo termina quando a primeira equipe ou jogador alcançar o ponto de chegada.

Vale ressaltar que o professor tem o total domínio sobre a aplicação do jogo, podendo manter no jogo somente as cartas correspondentes aos conteúdos já ministrados por ele em sala. Outras adaptações também podem ser feitas, como exemplo, no quarto nível ser cobrado dos jogadores exemplos de questões onde a respectiva grandeza física é cobrada.

Ao final da aplicação do jogo, o questionário apresentado na Figura 4, foi aplicado. A partir das respostas fornecida pelos entrevistados, os dados foram analisados e apresentados a seguir.

\section{RESULTADOS E DISCUSSÕES}

Os resultados aqui apresentados estão divididos em duas etapas, a primeira relacionado a observação do comportamento dos participantes durante a aplicação do jogo, e a segunda referente às respostas 
Revista do Professor de Física • Brasília, vol. 2, n. 2 • 2018

\begin{tabular}{l} 
1. O que o você achou do jogo? ( ) Ótimo ( ) Bom ( ) Regular ( ) Ruim. \\
2. O que poderia ser melhorado no jogo? \\
\hline $\begin{array}{l}\text { 3. Você achou o jogo dificil? ( ) Sim ( ) Não. } \\
\text { Justifique: }\end{array}$ \\
$\begin{array}{l}\text { 4. Quais conteúdos (grandezas fisicas) abordados no jogo que você não estudou no ensino médio ou na } \\
\text { graduação? }\end{array}$ \\
\hline $\begin{array}{l}\text { 5. Você considera importante o uso de jogos para o ensino de fisica? ( ) Sim ( ) Não. } \\
\text { Justifique: }\end{array}$ \\
\hline $\begin{array}{l}\text { 6. Baseado na realidade do estado do Acre, você considera que seria possivel aplicar recursos } \\
\text { didáticos, como o jogo nas escolas públicas? ( ) Sim ( ) Não. }\end{array}$ \\
\hline
\end{tabular}

Figura 4: Questionário aplicado ao final da atividade.

fornecidas pelos entrevistados sobre o jogo proposto. O jogo foi executado na turma de oitavo período, concluintes do Curso de Licenciatura em Física da UFAC, na aula de Instrumentação do Ensino de Física V, ao longo do período letivo de 2017-2. Verificou-se que os futuros docentes, participaram da atividade com muito entusiasmos. Sendo o jogo muito elogiado pelos graduandos, que afirmaram durante a aplicação do mesmo que a dinâmica elaborada é muito interessante. Ao final do jogo, executado com êxito, duas equipes entre as três competidoras foram consideradas vencedoras com empate técnico.

Além da observação da atividade, o questionário opinário (Figura 4) foi aplicado. O total de participantes do jogo e respondentes ao questionário foram de 25 alunos. A primeira pergunta investigava a opinião dos pesquisados sobre o jogo. Os resultados mostram que $92 \%$ dos entrevistados acharam o jogo ótimo e $8 \%$ bom. Observe que os estudantes avaliaram interessante o uso do jogo, legitimando o uso do mesmo.

Vale ressaltar que o "Jogo das Grandezas" inicialmente, em fase experimental, foi aplicado para turma de primeiro período do Curso de Licenciatura da UFAC, na aula da disciplina de Instrumentação do Ensino de Física I, durante o período letivo de 2017-1. Durante a execução desta prática, a empolgação e entusiasmo entre os jogadores também foi observado, confirmando o bem estar que o jogo proposto propicia nos estudantes.

Como o "Jogo das Grandeza" ainda está em fase de adaptações e melhorias, a segunda pergunta avaliava, no ponto de vista dos entrevistados, pontos no qual o jogo poderia ser melhorado. Veja alguns exemplos das considerações apontadas pelos graduandos na Tabela 1.

Observe que a fala do Aluno 5 vai de encontro ao fato de que as grandezas usadas no jogo estão descritas nas cartas, de forma que o professor da disciplina pode selecionar as cartas que deseja usar com sua respectiva turma. Neste caso, o professor pode optar por usar com determinada classe, somente as 
Revista do Professor de Física • Brasília, vol. 2, n. 2 • 2018

Tabela 1: Apontamentos citados pelos entrevistados, sobre melhorias para o "Jogo das Grandezas".

\begin{tabular}{|c|c|}
\hline \multicolumn{2}{|c|}{ Questão: O que poderia ser melhorado no jogo? } \\
\hline Aluno 1: & "Poderia ser dado dicas ou opções nas cartas." \\
\hline Aluno 2: & "Aumentar o número de perguntas e dividir em fácil, médio e difícil." \\
\hline Aluno 3: & "Melhorar o padrão de respostas do último nível.” \\
\hline Aluno 4: & "Nas definições poderia ser explicado melhor utilizando exemplos." \\
\hline Aluno 5: & "Poderia ser adaptado para realidade do ensino médio.” \\
\hline
\end{tabular}

cartas correspondentes às grandezas físicas ensinadas por ele em sala de aula. Desta forma, o professor pode estabelecer as adaptações necessárias para a realidade do público no qual pretende aplicar o jogo.

Com relação às dificuldades do jogo, verificou-se que $64 \%$ dos graduandos não encontraram complexidade em participar do jogo, enquanto que 36\% afirmaram ter problemas para responder algumas questões contidas no jogo. Este percentual de dificuldade em executar o jogo proposto pode estar relacionado principalmente ao pouco domínio e conhecimento sobre alguns conteúdos relacionados à: Física Moderna, Ondulatória, Eletromagnetismo e Óptica, conforme respostas obtidas à quarta pergunta do questionário, que investigava quais grandezas físicas, abordadas no jogo, os entrevistados não haviam estudado no ensino médio ou na graduação.

Entre os 64\% que afirmaram não encontrar dificuldades no jogo, vale destacar as seguintes justificativas:

- "Pois com os conhecimentos obtidos em física se torna fácil";

- "As perguntas estavam de acordo com os conteúdos estudados";

Entre os $36 \%$ que relataram dificuldades no jogo, vale mencionar a justificativa: "Pela alta abrangência de conteúdos", evidenciando a dificuldade que estudantes mostraram ao tentar lembrar de todos os conteúdos.Observe que a complexidade em responder algumas questões está relacionado ao leque de conteúdos trabalhados através do jogo proposto. Ressaltando que o jogo cumpriu com sua finalidade de fazer uma revisão dos conteúdos estudados na componente curricular de física. Para suprir este problema, sugere-se fazer uma revisão dos conteúdos antes da aplicação do jogo.

Mediante a análise dos questionários, constatou-se que todos os alunos apontam como importante o uso de jogos para o ensino de física, especialmente para o ensino médio, evidenciando o fato de este recurso representar uma ferramenta promissora para facilitar o processo de ensino-aprendizagem, inserindo os estudantes ativamente das aulas.

Confirmando este fato, $96 \%$ dos alunos responderam que os jogos didáticos poderiam ser aplicados nas escolas públicas de educação básica no Estado Acre, enquanto de 4\% (apenas um aluno) afirmou que não.

\section{CONSIDERAÇÕES FINAIS}

O presente trabalho propõe o "Jogo das Grandezas" escalares e vetoriais como um recurso didático para o ensino de física. O mesmo engloba os principais conteúdos estudados na componente curricular de 
física, representando uma ferramenta interessante para ser aplicada nas turmas de terceiro ano do ensino médio e nos últimos períodos da graduação em física, onde o professor de física pode estabelecer as adaptações necessárias para o público alvo em que a atividade for aplicada.

Com base nos resultados e discussões apresentadas, é possível concluir que os objetivos de despertar interesse dos estudantes durante a aula, melhorar o desempenho dos mesmos, facilitar a aprendizagem de determinados conteúdos, realizar uma avaliação geral sobre os conhecimentos de física da turma, entre outros, podem ser trabalhados com a aplicação do "Jogos das Grandezas". Vale ressaltar que a utilização de jogos pedagógicos, facilitam a compreensão dos conteúdos, além de promover a interação e participação dos estudantes na atividade proposta. Tais recursos estimulam, potencialmente, cognição, afeição, socialização, motivação e a criatividade. Considera-se ainda que com a aplicação do jogo pode-se estabelecer uma importante relação de concordância entre a teoria e prática.

A qualidade das opiniões expressas pelos estudantes a respeito do jogo proposto pode ser atribuída aofator lúdico por exemplo, fator fundamental para a condução da atividade e para produzir um bom aproveitamento. O "Jogo das Grandezas", a partir das informações fornecidas pelos participantes da pesquisa, será aperfeiçoado e melhorado para futuras aplicações. Contudo, o mesmo já representa um recurso promissor para o ensino de física.

\section{Referências}

[1] BEZERRA, D. P.; GOMES, E. C. S.; MELO, E. S. N.; SOUZA, T. C. A evolução do ensino da física - perspectiva docente. Scientia Plena, 5, 094401.1-094401.8 (2009).

[2] BRASIL. Ministério da Educação. PCN+ Ensino Médio, Orientações Educacionais Complementares aos Parâmetros Curriculares Nacionais. Ciências da Natureza, Matemática e suas Tecnologias, Vol. 2. Brasília: MEC/SEF, 2002.

[3] CARDOSO, L. R.; PARAÍSO, M. A., Álbum fotográfico: um mapa de cenários discursivos na produção acadêmica brasileira sobre aulas experimentais de Ciências. Ciência \& Educação, Bauru 20, (1) 83-115 (2014).

[4] CARVAlHO, A. M. P.; PÉREZ, D. G. Formação de Professores de Ciências: tendências e inovações. 9a. Edição. São Paulo, Cortez Editora, 2011.

[5] CASTElO BRANCO, A. R. M.; MOUTINHO, P. E. C., O lúdico no ensino de física: o uso de gincana envolvendo experimentos físicos como método de ensino. Caderno de Física da UEFS 13, (2) 2601.1-2601.8 (2015).

[6] FREIRE, P. Pedagogia da autonomia: saberes necessários à prática educativa. 43a. Edição. São Paulo, Paz e Terra, 2011.

[7] GOMES, R. R.; FRIEDRICH, M., A Contribuição dos jogos didáticos na aprendizagem de conteúdos de Ciências e Biologia. In: EREBIO, Rio de Janeiro 1, 389-392 (2001). 
[8] HECKLER, V.; SARAIVA, M. F. O.; FILHO, K. S. O. Uso de simuladores, imagens e animações como ferramentas auxiliares no ensino/aprendizagem de óptica. Rev Bras Ens de Física 29, (2) 267-273 (2007).

[9] MESSEDER NETO, H. S.; MORADILLO, E. F.; O jogo no ensino de química e a mobilização da atenção e da emoção na apropriação do conteúdo científico: aportes da psicologia histórico-cultural. Ciência \& Educação, Bauru 23, (2) 523-540 (2017).

[10] MORAES, J. U. P., A visão dos alunos sobre o ensino de física: um estudo de caso. SCIENTIA PLENA 5, (11) 114809.1-114809.7 (2009).

[11] MOREIRA. M. A. Teorias de aprendizagem. 2a. Edição. São Paulo, Editora Pedagógica e Universitária, 2015.

[12] MOREIRA, M. A. Grandes desafios no ensino de Física na educação contemporânea. Rev Prof de Física, Brasília 1, (1) 1-13 (2017).

[13] PEREIRA M. L. D’A. A.; OLIVEIRA, P. E. D. F., Física em Ação através de Tirinhas e Histórias em Quadrinhos. Cad Bras Ens de Física 33, (3) 896-926 (2016).

[14] PIASSI, L. P., A ficção científica e o estranhamento cognitivo no ensino de ciências: estudos críticos e propostas de sala de aula. Ciência \& Educação, Bauru 19, (1) 151-168 (2013).

[15] PULOSKI, M. A. S.; Compreendendo Piaget: uma introdução ao desenvolvimento cognitivo da criança. 2a. Edição. Rio de Janeiro, Zahar, 1983.

[16] REGO, T. C. Vygostsky: uma perspectiva histórico-cultural da educação, 12a. Edição. Petrópolis, Vozes, 2001.

[17] RICARDO, E. C.; FREIRE, J. C.A., A concepção dos alunos sobre a física do ensino médio: um estudo exploratório. Rev Bras Ens de Física 29, (2) 251-266 (2007).

[18] SCHNETZLER, R. P.; A pesquisa em ensino de química no Brasil: conquistas e perspectivas. Química Nova 25, Supl. 1 14-24 (2002).

[19] SCHWARZ, V. R. K. Contribuição dos jogos educativos na qualificação do trabalho docente. Dissertação (Programa de Pós-Graduação em Educação em Ciências e Matemática) - Faculdade De Física, Pontifícia Universidade Católica Do Rio Grande Do Sul, Porto Alegre, 2006. 